\title{
Choices in Surgery for Older Women with Breast Cancer
}

\author{
Vikram Swaminathan $^{a} \quad$ Markos K. Spiliopoulos $^{b}$ Riccardo A. Audisio ${ }^{c}$ \\ ${ }^{a}$ FY2 Surgery, Southport and Ormskirk NHS Trust, Liverpool, England, UK \\ ${ }^{b}$ Faculty of Medicine, Democritus University of Thrace, Athens, Greece \\ ${ }^{\circ}$ Consultant Breast Oncological Surgeon, St Helens Teaching Hospital, St Helens, UK
}

\author{
Keywords \\ Breast cancer · Surgery · Oncology · Geriatric · Elderly
}

\section{Summary}

Breast cancer is a major cause of mortality worldwide. As the population ages and life expectancy increases, the burden of cancer on health services will increase. Older patients with breast cancer are becoming more suitable for surgery; tailored surgical techniques and increasing healthy life expectancy alongside improved assessment of patients are aiding this trend. Surgery is also becoming a favoured treatment of personal choice for older patient with breast cancer. Evidence shows that surgery is almost always feasible for the older patient with outcomes (survival, progression, and recurrence rates) comparable to younger groups and superior to non-surgical treatments. We aim to describe the current status of surgery for the older patient with breast cancer, showing it is an option that should not be denied. Surgery should always be considered regardless of age, after evaluation of co-morbidities.

\section{Introduction}

Breast cancer is a major cause of mortality in the current world population. The number of elderly is estimated to more than double by 2040 to 1.3 billion; $14 \%$ of the world's population will be of retirement age [1]. As the population ages and life expectancy increases, the burden of cancer on health

\section{Schlüsselwörter \\ Mammakarzinom - Chirurgische Behandlung . Onkologie · Geriatrisch · Ältere Patientinnen}

\section{Zusammenfassung}

Brustkrebs ist eine der weltweit häufigsten Sterbeursachen. Die älter werdende Bevölkerung und zunehmende Lebenserwartung führen dazu, dass die Gesundheitsversorgung stärker belastet wird. Für ältere Patientinnen mit Mammakarzinomen besteht zunehmend die Option der chirurgischen Versorgung, was durch maßgeschneiderte chirurgische Verfahren, eine höhere gesunde Lebenserwartung und verbesserte Patientenuntersuchungen unterstützt wird. Desweiteren wird die chirurgische Behandlung zunehmend zur bevorzugten Therapieform der persönlichen Wahl bei älteren Mammakarzinompatientinnen. Studien haben gezeigt, dass die chirurgische Behandlung bei fast allen älteren Patientinnen möglich ist und ein Outcome (Überleben, Progression und Rezidivrate) erzielt, das mit dem jüngerer Patientengruppen vergleichbar ist und dem Outcome nichtchirurgischer Therapieansätze überlegen ist. Ziel dieser Übersichtsarbeit ist es, den aktuellen Stand der chirurgischen Versorgung älterer Mammakarzinompatientinnen zu beschreiben und ihren Wert als eine nicht zu unterschlagende Therapieoption aufzuzeigen. Nach Einschätzung existierender Komorbiditäten sollte die chirurgische Versorung unabhängig vom Alter in jedem Fall in Erwägung gezogen werden.

services will increase, not only with regards to the numbers of people developing cancer but also the long-term management of these patients. In turn, older patients may be suitable for surgical procedures which in the past, when life expectancy was lower, may not have been a viable option or in the best interest of the patient after risk-benefit analysis. Surgery may still be perceived as not safe for the older patient, especially at

\section{KARGER \\ Fax +497614520714 \\ Information@Karger.de}

www.karger.com (c) 2012 S. Karger GmbH, Freiburg

$1661-3791 / 12 / 0076-0445 \$ 38.00 / 0$

Accessible online at:

www.karger.com/brc
Dr. Vikram Swaminathan

Surgical Department

Southport District General Hospita

Town Lane, Kew, Liverpool PR8 6PN, UK

vikramswaminathan@hotmail.com 
the extremities of age. The arbitrary definition of an older person (elderly) is commonly thought to be around the age of 60 years and over, and the United Nations agreed on a cut-off age of 60 years when referring to the older population [2]. However, this goalpost is changing together with descriptive epidemiology. Is it appropriate to categorize patients based on age groups, or should a patient's fitness status, current quality of life and frailty status (amongst other factors) be considered instead of just chronological age? The implications of this would cause the 'older' group to increase in size, with the consequence that many more patients may be suitable for more aggressive management of breast cancer, including surgery. This is a problem that will in turn increase the burden on already restricted resources, and breast cancer is thus an important condition to consider when calculating health needs and managing equity.

Statistics show that all nations are experiencing growth in their number of elderly residents. Interestingly, population aging is becoming 'deeper' as the most rapid growth occurs in the oldest age groups, mostly oldest-old $(80+$ or $85+$ years $)$ and centenarians $(100+$ years $)$. This means that the population is being accumulated with particularly old and frail people. In addition, the 'feminization' of population aging is also worth highlighting. In the United States, there were 20.6 million older women and 14.4 million older men in 2000 (ratio of 143:100). The female to male ratio increases with age, reaching 245 for persons 85 and over [3]. Excluding skin cancers, breast cancer is the most common malignancy among women in most of the developed world [4], and it is second only to lung cancer as the leading cause of cancer death among women worldwide [5, 6]. It seems that older women represent the fastest growing segment of the population in the United States and Europe. Therefore, during the coming decades, older women will represent an increased cohort of both patients with newly diagnosed disease and survivors [4].

One of the greatest risks for developing breast cancer is prolonged oestrogen exposure, which explains why breast cancer incidence increases with advancing age [7]. It is not an exaggeration to say that aging is one of the single greatest risk factors for the development of new breast carcinoma [4]. A woman's lifetime risk is estimated as $9 \%$; this is a population-based estimate that means 1 in $8-9$ women will develop breast cancer at some point during their lives [7, 8]. For an individual woman, risk is largely based on age and is often estimated by decade. After menopause, and particularly after age 65, the risk increases several-fold [7]. Approximately 50\% of breast carcinomas occur in women $\geq 65$ years, and $>30 \%$ of breast carcinomas occur among women $>70$ years [4]. As breast cancer incidence increases with increasing age, the described changing demographics and continuously increasing life expectancy will further enlarge the number of older women confronted with breast cancer [9].

Studies have shown that older patients may experience undertreatment [10]. Older patients have lower odds of receiving standard care, and increased age at diagnosis predicts deviation from guidelines for surgical therapy $[9,11]$. Therefore, it is crucial that the unique challenges posed by older women need to be carefully addressed in order to optimize breast cancer care in this population, especially in the area of surgery [7].

\section{A Patient's Perspective}

In the current era of medical management, many options are available to a patient with breast cancer. Increasingly, these options are also available to the older cohort of breast cancer patients, and breast conserving surgery has been shown to have increased in the older age group (50+) over time [12]. People are not only living longer but also living healthy for longer. As medical management improves, functioning is maintained to a greater age. Because of these factors, patients expect more. Cancer is no longer seen as a death sentence, and surgery is often seen as a cure for the condition. A patient may also have goals in life that they wish to work towards; surgery then becomes key as treatment for breast cancer, or even 'palliative' in some cases to maintain quality of life so that the patient's wishes or life goals may be fulfilled. The options need to be weighed up and discussed carefully with the patient. In some cases, surgery may not be the best option; risks are always involved, and there can never be a guarantee of safe passage postoperatively. Several studies have evaluated the expectations of older women with breast cancer. It has been shown that the level of acceptance of treatment does not differ among younger and older patients. The main concern of older women seems to be that their quality of life and independence remains unaffected [13,14]. It is also noted that elderly women rely greatly on advice from practitioners when making their treatment choices [14-17]. Thus it is imperative that information is provided clearly regarding disease prognosis, treatment options, and possible related side effects when counselling elderly women with breast cancer. Patients should also be informed about the negative impact of undertreatment on disease outcome [18]. Breast surgery has undergone important changes over the last decades: screening and patient awareness have resulted in less radical/extensive surgery. Patients are more frequently suitable for wide excision and limited axillary dissection, and in the case of very high surgical risk patients, the operation can be performed under local and/or regional anaesthesia $[19,20]$. With these advances in mind, it is important to always keep open the option of surgery for older patients with breast cancer. Patients should be clearly informed that a surgical option is feasible in almost all cases, with a negligible operative risk. Before embarking on the discussion of surgical versus non-surgical treatment options, it is mandatory to attempt to understand what older cancer patients are asking for and what their targets and priorities are. 


\section{Surgical Options for Older Breast Cancer Patients}

\section{Advantages of Surgery over Primary Endocrine Treatment}

Surgical treatment ranges from simple local excision to various forms of wider excision such as segmental resection, quadrantectomy, and procedures such as the entire removal of the mammary gland, i.e. mastectomy [21]. During the past 2 decades, studies have been conducted with the purpose of determining the pros and cons of surgery and primary endocrine therapy. 2 randomized trials $[22,23]$ not only showed no difference in survival between elderly patients treated with tamoxifen alone or surgery alone, but also (even if not statistically significant) that locoregional control was better in the surgery group [24]. Similar results were obtained by the Cancer Research Campaign UK [25] comparing tamoxifen alone versus surgery followed by tamoxifen in women aged over 70 years with operable breast cancer [24]. In the Creta trial [24] where the efficacy of tamoxifen as primary treatment in women aged over 70 years with operable breast cancer versus surgery followed by adjuvant tamoxifen was evaluated, no difference between groups emerged in overall and breast cancer survival [24]. Recently, in a Cochrane review conducted by Hind et al. [26], the clinical efficacy of endocrine therapy alone in women aged 70 years or over and who are fit for surgery was again evaluated. This review was unable to determine a statistically significant difference in favour of either surgery or primary endocrine therapy in respect of overall survival. However, there was a statistically significant difference in terms of progression-free survival, which favoured surgery with or without endocrine therapy [26]. This bares important implications on the quality of life that patients experience in the presence of a locally recurrent cancer, often ulcerating the skin, bleeding, and presenting signs of infection. The reduced local progression rate with surgery plus endocrine treatment compared with primary endocrine therapy alone is thus extensively documented, and older women should not be denied a surgical option on the basis of their anagraphic age. Surgery seems to offer better local control; however, primary endocrine therapy is still an appropriate option for women with oestrogen receptor (ER)-positive tumours, who are unfit for or refuse surgery. Therefore, in ER-positive patients with a short life expectancy (i.e. $<2$ years), considered unfit for/or refusing surgery after optimization of their general medical condition, primary endocrine therapy should be considered [26, 27], although in 1 trial including cases with high ER content tumours [28] it was found that local control was superior with surgery and adjuvant endocrine therapy [26]. Patients $>80$ years old tend to have more ER-positive tumours (85-90\%) as compared to women $<80$ years of age [26]. Thus, tamoxifen is currently being considered in the management of these patients, such as patients with hormone-positive ductal carcinoma in situ (DCIS) $(75 \%$ of DCIS are ER-positive) and patients without risk factors for the potential side effects such as mentioned below [21].

\section{Feasibility and Extent of Breast Surgery}

Patient selection and tailored treatment are crucially important. The surgical group is now increasing; older patients not only remain healthy for longer but surgical techniques are evolving to minimize related risks. The 2 fundamental available options for younger patients, i.e. mastectomy or wide local excision plus radiotherapy, are relevant to the older age group as well. Cancer-related survival for these 2 methods is equivalent, although there is a slightly higher rate of long-term local control for women who undergo mastectomy. The importance of local control on long-term overall survival outcomes has been highlighted by the recent overview analysis of the Early Breast Cancer Trialists' Collaborative Group. This confirmed the importance of adequate local treatment in the management of primary operable breast cancer. Of importance was the finding of a small but significant survival advantage at 15 years for patients treated with adjuvant radiotherapy post surgery. The advantage in the mastectomy group was predominantly seen in patients with axillary node involvement; the survival benefit for patients treated with breast conservation was independent of nodal status [29]. Indications for mastectomy include large primary tumours (UICC TNM stage T3) and multifocal disease within more than 1 quadrant of the breast, regardless of patient age. A patient with a relatively large tumour in a smaller breast may also be a candidate for mastectomy. Another factor for mastectomy is patient preference. A recent UK audit demonstrated that a significant proportion of patients with small tumours suitable for breast conservation surgery prefer mastectomy if given the choice [30]. In older breast cancer patients, the primary tumour size is slightly larger than the average; this may explain the increased mastectomy rate in this age group. There is also a thought that older women are less concerned by the cosmetic appearance post mastectomy; this however should be discussed on a patient-by-patient basis when presenting surgical options, bearing in mind that older women might still be interested in preserving their body image while aiming to improved cosmetic results [31]. Finally, it is important to take into account the environment in which the patient lives and their potential compliance with the treatment; as any breast-sparing procedure entails the need for adjuvant radiation therapy to the remaining gland, the patient needs to be informed about this. While some countries offer full support to all patients (including free transportation to the radiotherapy department), others do not, and this may pose significant problems to older women with no familial support.

Fitness for surgery is often taken into account with respect to the surgical choice: wide local excision may well be performed under local anaesthesia (LA) and so does mastectomy, particularly where dedicated anaesthetists are able to assist with adequate nerve blocking techniques. A series of mastectomies under LA demonstrated that LA mastectomy was feasible and rarely demanded the use of harmful levels of local anaesthetics [32]. The benefits of LA or regional anaes- 
thesia include low rates of postoperative nausea and vomiting as well as excellent pain control [33]. Wide local excision is almost always possible under LA, whereas for a larger breasted woman mastectomy under LA may not be feasible due to the toxicity of large volumes of local anaesthetic. Exadaktylos et al. [34] reported reduced local recurrence rates and improved metastasis-free survival when paravertebral block (PVB) regional anaesthesia was used instead of general anaesthesia. Axillary sampling is also possible under LA, but the same does not apply for axillary clearance [35]. The advantages of thoracic PVB are the avoidance of the potential complications of a thoracic epidural anaesthesia, reduced postoperative pain, reduced postoperative nausea, and decreased chronic pain after breast surgery [36]. Finally, postoperative comfort is crucially important for a prompt recovery: there is thus a role for the use of LA in view of reduced postoperative nausea and vomiting and decreased pain. It is important to understand that operative mortality rates are nowadays negligible if not anecdotal $(0-0.3 \%)$ [37]; there is thus no excuse to neglect surgery on the grounds of anaesthetic risk.

\section{Cosmetic Surgery for Older Women}

Involvement of plastic surgeons also allows for breast reconstruction post resection. There are 2 main types of surgical breast reconstruction techniques, autogenous and implantbased. Presently among autogenous breast reconstructions, pedicled or free transverse rectus abdominis muscle (TRAM) flap, deep inferior epigastric perforator (DIEP) flap, superficial inferior epigastric perforator (SIEP) flap, and extended latissimus dorsi flap are the most common operations. Other procedures offered are inferior or superior gluteal artery perforator (I-GAP or S-GAP) flap and transverse upper gracilis (TUG) flap. Several studies have compared the use of autogenous reconstruction with implant-based reconstruction. August et al. [38] found no significant difference in complication rate according to the type of reconstruction in older women, but found that $22.8 \%$ of younger women had complications after autogenous reconstruction, compared to $64 \%$ after prosthetic reconstruction. Chang et al. [39] noted that breast site complications were more common in implantbased reconstruction ( $77 \%$ compared to $38 \%$ in autogenous tissue reconstruction). $31 \%$ of patients with autogenous tissue reconstruction did experience a donor site complication. Girotto et al. [40] did not consider differences in complication rates between the 2 procedures, but did note that autogenous tissue was preferable to implants in terms of pain and role limitation. Despite the variation in individual results post reconstruction, it is noticeable that the available evidence suggests that breast reconstruction is not only a safe and feasible option in older women, but also has the potential to provide great improvement in quality of life after a mastec- tomy. Furthermore, the use of autologous tissue reconstruction can be recommended and has many benefits despite the increased complexity of the procedure. Individual consideration of each patient's co-morbidities and surgical risk should be made before recommending reconstruction. Age should not be a factor in this consideration.

\section{Management of the Axilla}

The presence of axillary lymph node metastasis in breast cancer patients is an important prognostic factor; this consequently influences the adjuvant management of such patients [41]. The role of an extensive axillary clearance (removal of all axillary lymph nodes) is also highly debated. The procedure is shown to have prognostic benefit; however, it is associated with upper limb morbidity which can be severe and debilitating at times, especially to an older patient. Lymphoedema is regarded as the most feared and problematic longterm complication [42]. To minimize the number of patients undergoing unnecessary axillary dissection, current practice relies on the use of preoperative ultrasonography of the axillary area and fine needle aspiration cytology of any suspicious node; if negative, patients are usually offered a sentinel lymph node biopsy (SLNB) to ascertain the presence of metastatic deposits [43]. The real advantages of axillary dissection are much debated; there are reports of survival gains in patients who undergo this procedure [44], while others report on the lack of advantages [45]. Further management recommendations include the use of minimal surgery (axillary sampling) to stage the axilla for patients with early invasive breast cancer and no evidence of lymph node involvement on ultrasonography or a needle biopsy; alternatively, targeted sampling may be considered (i.e. SLNB) [46].

\section{Feasibility and Reliability of SLNB in Older Women}

Axillary lymph nodes are the most common site of metastasis in breast carcinoma [47]. The sentinel node ( $\mathrm{SN}$ ) is the first node to drain through the lymphatics from the primary tumour making the axillary lymph nodes the most frequent site of metastasis from breast neoplasms. Due to the widespread use of mammography, breast cancers are consistently being diagnosed at the earliest stages of disease resulting in a reduced axillary involvement with only $10 \%$ of tumours equal to or less than $1 \mathrm{~cm}$ demonstrating axillary metastases [48].

The use of axillary dissection for breast cancer staging purposes has rapidly been replaced by SLNB which has emerged as the procedure of choice in evaluating the axilla, and so axillary dissection is avoided in patients with no involved nodes. The technique was first used by Morton et al. [62] with blue dye and later by Van der Veen et al. [63] with lymphoscintigraphy to select melanoma patients for regional node dissection [47]. The use of SLNB is applicable to most breast cancer patients, with only a small fraction of patients 
who are unsuitable or have disease-related factors that may compromise its success (i.e. previous axillary surgery or radiotherapy). Rare complications of this technique have been reported and are usually attributed to the injection dye used. The most common are pulmonary oedema and anaphylactic reactions in approximately $1-3 \%$ of patients [48]. Since the first report of SLNB for breast cancer, this technique has proven to be feasible and has been deemed appropriate for use in place of axillary dissection with a high degree of accuracy, a low false-negative rate, low morbidity, and a low axillary relapse rate [49]. Demographically, the application of SLNB in patients with breast cancer has progressively increased from $26.5 \%$ in 1998 to $65.5 \%$ in 2005 according to 1 study [48]. SLNB has thus now become the new standard of care for nodal staging in early-stage breast disease [43, 47]. It is reported to predict the status of the remaining axillary lymph nodes in early breast cancer with an accuracy of 95 $97 \%$ and false-negative rates of $0-13 \%$ [49]. SLNB was initially indicated for unifocal, infiltrating, and clinically nodenegative breast carcinomas of up to $3 \mathrm{~cm}$ in diameter. Its use was not recommended in pregnancy, after neo-adjuvant chemotherapy, after previous breast and axillary surgery, and for infiltrating multicentric and multifocal carcinomas. Authors have since concluded that a combination technique improves the SLN identification rate in both early and advanced breast disease [48]. We can conclude that the accuracy of SLNB in metastatic breast cancer is comparable to that obtained in unifocal disease [50].

\section{Decision for Surgery}

The decision for surgery in older people needs to involve many factors, as previously mentioned. DCIS poses a problem, given that a premalignant condition may indicate aggressive management with all associated risks in the face of a nonlife-threatening disease. Age alone may not be an accurate predictor of treatment outcome [46]. A study into DCIS in older patients ( $>50$ years of age) showed no excessive mortality from surgery in this age group [5]. Overall, the decision for surgical management is not only based on evidence, but also on patient assessment as well as patient expectations.

\section{Assessing for Frailty}

The use of nomograms and scoring systems can help to provide evidence to make a decision for or against surgery in an older patient. One of the first to be developed was the Charlson Index which considers both the number and severity of a defined selection of co-morbid diseases and can predict mortality with modest accuracy [51]. Other screening tools include the Comprehensive Geriatric Assessment (CGA) and the Multidimensional Assessment for Cancer in the Elderly
(MACE). They are multidisciplinary management tools aimed at determining an older person's medical, psychological, and functional capability [52]. This includes assessment of current diagnoses, medications, nutritional status, physical function, psychological evaluation, and social and environmental appraisals. Literature suggests that CGA may be useful with regard to treatment decision-making in older cancer patients; this is consistent with the clinical and pilot research experience published by some authors [37, 53, 54].

Measurement of global functional ability has also been shown to be independently useful in predicting life expectancy; the Activities of Daily Living (ADL), the Instrumental Activities of Daily Living (IADL), and the Mini Mental State Examination (MMSE) scores have all been shown to have prognostic value [53, 55-58]. Quick screening tools should be used by clinicians alongside independent factors/indications for surgery and current evidence in order to provide a thorough assessment and identify frailty and the ability of older women to undergo surgery for breast cancer [59].

Frailty is a factor that is crucial in modern times for assessing older patients who are fit to undergo more invasive/aggressive management [54]. Thus tools have been developed (Groningen Frailty Index, GFI; Vulnerable Elders Survey, VES13; Timed Up-and-Go, TUG) with the purpose of screening older cancer patients for frailty, in addition to the CGA. Geriatric syndromes are closely linked with the management of cancer in these older patients, thus assessment of frailty is important in modern management. The presence of multiple co-morbidities also affects outcome of surgery for older breast cancer patients and can increase the risk of death from causes other than breast cancer $[60,61]$. There thus may be circumstances where non-operative therapies or even no treatment may be considered preferable due to these patient factors and evaluations. Surgeons must be able to apply all available options in the best interest of the patient and allow the informed patient to decide which way to proceed. The stigma attached to older patients being unfit for surgery must be cast aside.

\section{Conclusion}

Breast cancer is becoming an increasing burden on healthcare across the globe as the population increases in number and age. It is important not to ignore the needs and wishes of the well-informed older patient when deciding on a modern approach to their management. Surgery in the elderly has been shown to offer advantages in terms of survival and local disease control. With the use of techniques to identify early metastatic spread (such as SLNB and axillary ultrasonography) and advancing preoperative management, surgery is an option that should always be considered regardless of the age of the patient. Further investigations are taking place to determine the most effective individualized treatment for breast cancer in older patients in an effort to avoid under- 
treatment as well as overtreatment. Individualised therapeutic plans require the full understanding of a patient's wishes and fitness, which is the leading way to improved surgical management of older breast cancer patients.

\section{Disclosure Statement}

The authors declare no conflict of interest and disclose no financial and personal relationships with other people or organizations that could inappropriately influence/bias this work.

\section{References}

1 Swaminathan V, Audisio RA: Geriatric oncology: a problem and solution. Oncology News, 2012; 7:1:12-3.

2 Swaminathan V, Audisio RA. Cancer in older patients: an analysis of elderly oncology. Ecancermedicalscience 2012;6:243.

3 Gavrilov LA, Heuveline P: Aging of population; in Demeny P, McNicoll G (eds): The Encyclopedia of Population. New York, NY, Macmillan Reference USA, 2003.

4 Gennari R, Curigliano G, et al.: Breast carcinoma in elderly women: features of disease presentation, choice of local and systemic treatments compared with younger postmenopausal patients. Cancer 2004;101:1302-10.

5 Bastiaannet E, van de Water W, Westendorp RGJ, Janssen-Heijnen MLG, Van de Velde CJH, de Craen AJM, et al.: No excess mortality in patients aged 50 years and older who received treatment for ductal carcinoma in situ of the breast. Int J Surg Oncol 2012;2012:567506.

6 6 DeSantis C, Siegel R, Bandi P, Jemal A: Breast cancer statistics, 2011. CA Cancer J Clin 2011;61: 409-18.

7 Gandhi S, Verma S: Early breast cancer in the older woman. Oncologist 2011;16:479-85.

8 Downs-Holmes C, Silverman P: Breast cancer: overview and updates. Nurse Pract 2011;36:20-6, quiz 7.

$\checkmark 9$ Van de Water W, Markopoulos C, van de Velde CJ, Seynaeve C, Hasenburg A, Rea D, Putter H, Nortier JW, de Craen AJ, Hille ET, Bastiaannet E, Hadji P, Westendorp RG, Liefers GJ, Jones SE: Association between age at diagnosis and diseasespecific mortality among postmenopausal women with hormone receptor-positive breast cancer. JAMA 2012;307:590-7.

10 Yancik R, Wesley MN, et al.: Effect of age and comorbidity in postmenopausal patients aged 55 and older. JAMA 2001;285:885-92.

11 Enger SM, Thwin SS, Buist DS, Field T, Frost F, Geiger AM, Lash TL, Prout M, Yood MU, Wei F, Silliman RA: Breast cancer treatment of older women in integrated health care settings. J Clin Oncol 2006;24:4377-83.

12 Estevez LG, Alvarez I, Segui MA, et al.: Current perspectives of treatment of ductal carcinoma in situ. Cancer Treat Rev 2012;36:507-17.

13 Yellen SB, Cella DF, Leslie WT: Age and clinical decision making in oncology patients. J Natl Cancer Inst 1994;86:1766-70.

14 Husain LS, Collins K, Reed M, Wyld L: Choices in cancer treatment: a qualitative study of the older women's ( $>70$ years) perspective. Psychooncology 2008; $17: 410-6$.

15 Ciambrone D: Treatment decision-making among older women with breast cancer. J Women Aging 2006;18:31-47.

16 Maly RC, Leake B, Silliman RA: Breast cancer treatment in older women: impact of the patientphysician interaction. J Am Geriatr Soc 2004;52: 1138-45.
17 Liang W, Burnett CB, Rowland JH, et al.: Communication between physicians and older women with localized breast cancer: implications for treatment and patient satisfaction. J Clin Oncol 2002;20:1008-16.

18 Bouchardy C, Rapiti E, Fioretta G, et al.: Undertreatment strongly decreases prognosis of breast cancer in elderly women. J Clin Oncol 2003;21:3580-7.

19 Doss NW, Ipe J, Crimi T, et al.: Continuous thoracic epidural anesthesia with $0.2 \%$ ropivacaine versus general anesthesia for perioperative management of modified radical mastectomy. Anesth Analg 2001;92: 1552-7.

20 Lynch EP, Welch KJ, Carabuena JM, et al.: Thoracic epidural anesthesia improves outcome after breast surgery. Ann Surg 1995;5:663-9.

21 Sakorafas GH, Farley DR, Peros G: Recent advances and current controversies in the management of DCIS of the breast. Cancer Treat Rev 2008;34:483-97.

22 Gazet JC, Ford HT, Coombes RC, Bland JM, Sutcliffe R, Quilliam J, Lowndes S: Prospective randomized trial of tamoxifen vs surgery in elderly patients with breast cancer. Eur J Surg Oncol 1994:20:207-14.

23 Robertson JF, Todd JH, Ellis IO, Elston CW, Blamey RW: Comparison of mastectomy with tamoxifen for treating elderly patients with operable breast cancer. BMJ 1988;297:511-4.

24 Mustacchi G, Ceccherini R, Milani S, Pluchinotta A, De Matteis A, Maiorino L, Farris A, Scanni A, Sasso F; Italian Cooperative Group GRETA: Tamoxifen alone versus adjuvant tamoxifen for operable breast cancer of the elderly: long-term results of the phase III randomized controlled multicenter GRETA trial. Ann Oncol 2003;14:414-20.

25 Bates T, Riley DL, Houghton J, Fallowfield L, Baum M: Breast cancer in elderly women: a Cancer Research Campaign trial comparing treatment with tamoxifen and optimal surgery with tamoxifen alone. The Elderly Breast Cancer Working Party. Br J Surg 1991;78:591-4.

26 Hind D, Wyld L, Reed M: Surgery vs. tamoxifen for operable primary breast cancer in older women: cochrane review. Br J Cancer 2007;96:1025-9.

27 Biganzoli L, Wildiers H, Oakman C, Marotti L, Loibl S, Kunkler I, Reed M, Ciatto S, Voogd AC, Brain E, Cutuli B, Terret C, Gosney M, Aapro M, Audisio R: Management of elderly patients with breast cancer: updated recommendations of the International Society of Geriatric Oncology (SIOG) and European Society of Breast Cancer Specialists (EUSOMA). Lancet Oncol 2012;13:e148-60.

28 Willsher PC, Robertson JFR, Jackson L, AlHilaly M, Blarney RW: Investigation of primary tamoxifen therapy for elderly patients with operable breast cancer. Breast 1997;6:150-4.

29 Reed MWR, Wyld L, Audisio RA: The surgical management of breast cancer in elderly women; in Reed MWR, Audisio RA (eds): Management of Breast Cancer in Older Women. London, Springer, 2010, pp. 197-211.
30 Breast Cancer Clinical Outcome Measures Project, BCCOM: Analysis of the management of symptomatic breast cancers diagnosed in 2004. West Midlands Cancer Investigation Unit, 3rd year report, Dec 2007. www.wmciu.nhs.uk/documents/ BCCOM\%20Year\%203\%20report.pdf.

31 Walton L, Ommen K, Audisio RA: Breast reconstruction in elderly women breast cancer: a review. Cancer Treat Rev 2011;37:353-7.

32 Oakley N, Dennison AR, Shorthouse AJ: A prospective audit of simple mastectomy under local anaesthesia. Eur J Surg Oncol 1996;22:134-6.

33 Kitowski NJ, Landercasper J, Gundrum JD, De Maiffe BM, Chestnut DH, Bottcher ML, et al.: Local and paravertebral block anesthesia for outpatient elective breast cancer surgery. Arch Surg 2010;145:592-4.

34 Exadaktylos AK, Buggy DJ, Moriarty DC, Mascha E, Sessler D: Can anesthetic technique for primary breast cancer surgery affect recurrence or metastasis? Anesthesiology 2006;105:660-4.

35 Reed MW, Audisio RA, Wyld L: The role of surgery in the treatment of older women with breast cancer. Clin Oncol (R Coll Radiol) 2009;21:103-10. Erratum in: Clin Oncol (R Coll Radiol). 2009;21:429.

36 Loader J, Ford P: Thoracic Paravertebral Block. Update in Anaesthesia. www.anaesthesiologists.org.

37 Parks RM, Hall L, Tang SW, Lakshmanan R, Hurria A, Winterbottom L, et al.: Evaluation of a cancer-specific comprehensive geriatric assessment (CGA) tool in older women with newly diagnosed primary breast cancer. 2011 ASCO Ann Meet Proc I. J Clin Oncol 2011;29:e19518.

38 August D, Rea T, Wilkins E: Breast reconstruction in older women. Surgery 1994;115:663-8.

39 Chang DW, Kuerer HM, Lipa JE, Robb GL, Youssef AA: Breast reconstruction in older women: advantages of autogenous tissue. Plast Reconstr Surg 2003;111:1110.

40 Girotto JA, Nahabedian MY, Schreiber J: Breast reconstruction in the elderly: preserving an excellent quality of life. Ann Plast Surg 2003;50:572.

41 Fisher B, Bauer M, Wickerham D, Redmond CK, Fisher ER: Relation of number of positive axillary nodes to the prognosis of patients with primary breast cancer: an NSABP update. Cancer 1983;52:1551-7.

42 Petrek JA, Heelan MC: Incidence of breast carcinoma-related lymphedema. Cancer 1998;83:277681.

43 Hall SJ, Brown SE, Porter GRJ, Steel J, Paisley K, Watkins RM, et al.: Axillary ultrasound in staging breast cancer: diagnostic accuracy and effect on subsequent axillary surgery - the Plymouth experience. Breast Cancer Res 2009;11(suppl 2):21.

44 Syed A, Garbos M, Patel A, Bradpiece H, Stephanie J: Role of axillary ultrasound in defining surgical management of breast cancer patients with nodal disease. Cancer Research 2009;69:suppl 3.

45 Martelli G, Miceli R, Daidone MG, Vetrella G, Cerrotta AM, Piromalli D, et al.: Axillary dissection versus no axillary dissection in elderly patients 
with breast cancer and no palpable axillary nodes: results after 15 years of follow-up. Ann Surg Oncol 2011;18:125-33.

46 Maas HA, Janssen-Heijnen ML, Olde Rikkert MG, Machteld Wymenga AN: Comprehensive geriatric assessment and its clinical impact in oncology. Eur J Cancer 2007;43:2161-9.

47 Veronesi U, Paganelli G, Galimberti V, Viale G, Zurrida S, Bedoni M, Costa A, de Cicco C, Geraghty JG, Luini A, Sacchini V, Veronesi P Sentinel-node biopsy to avoid axillary dissection in breast cancer with clinically negative lymph-nodes. Lancet 1997;349:1864-7.

48 Salem A: Sentinel lymph node biopsy in breast cancer: a comprehensive literature review. J Surg Educ 2009:66:267-75.

49 Lo YF, Cheung YC, Hsueh S, Ho KC: Feasibility of sentinel lymph node biopsy in multifocal/ multicentric breast cancer. Chang Gung Med J 2009;32:51-8.

50 Cipolla C, Vieni S, Fricano S, Cabibi D, Graceffa G, Costa R, Latteri S, Latteri MA: The accuracy of sentinel lymph node biopsy in the treatment of multicentric invasive breast cancer using a subareolar injection of tracer. World J Surg 2008; 32:2483-7.

\$5 Charlson ME, Pompei P, Ales KL, et al.: A new method of classifying prognostic comorbidity in longitudinal studies: development and validation. J Chronic Dis 1987;40:373-83.

52 Morris J: Comprehensive Assessment for the Older Frail Person in Hospital. British Geriatrics Society, 2005. www.bgs.org.uk.

53 Pope D, Ramesh H, Gennari R, Corsini G, Maffezzini M, Hoekstra HJ, Mobarak D, Sunouchi K, Stotter A, West C, Audisio RA: Pre-operative assessment of cancer in the elderly (PACE): a comprehensive assessment of underlying characteristics of elderly cancer patients prior to elective surgery. Surg Oncol 2006;15:189-97.

54 Audisio RA, van Leeuwen B: When reporting on older patients with cancer, frailty information is needed. Ann Surg Oncol 2011;18:4-5.

55 Repetto L, Fratino L, Audisio RA, et al.: Comprehensive geriatric assessment adds information to Eastern Cooperative Oncology Group performance status in elderly cancer patients: an Italian Group for Geriatric Oncology Study. J Clin Oncol 2002;20:494-502.

56 Inouye SK, Peduzzi PN, Robison JT, et al.: Importance of functional measures in predicting mortality among older hospitalized patients. JAMA 1998;279:1187-93.

57 Audisio RA, Ramesh H, Longo WE, et al.: Preoperative assessment of surgical risk in oncogeriatric patients. Oncologist 2005;10:262-8.
58 Fried LP, Tangen CM, Walston J, et al. Frailty in older adults: evidence for a phenotype. J Geronto A Biol Sci Med Sci 2001;56:M146-56.

59 PACE participants, Audisio RA, Pope D, Ramesh HS, Gennari R, et al.: Shall we operate? Preoperative assessment in elderly cancer patients (PACE) can help - a SIOG surgical task force prospective study. Crit Rev Oncol Hematol 2008;65:156-63.

60 Mann E, Koller M, Mann C, van der Cammen T, Steurer J: Comprehensive Geriatric Assessment (CGA) in general practice: results from a pilot study in Vorarlberg. Austria BMC Geriatr 2004;4:4.

61 Extermann M, Meyer J, McGinnis M, Crocker TT Corcoran MB, Yoder J: A comprehensive geriatric intervention detects multiple problems in older breast cancer patients. Crit Rev Oncol Hematol 2004;49:69-75.

62 Morton DL, Wen DR, Wong JH, et al.: Technical details of intraoperative lymphatic mapping for early stage melanoma. Arch Surg 1992;127:392399.

63 Van der Veen H, Hoekstra OS, Paul MA, et al.: Gamma probe guided sentinel node biopsy to select patients with melanoma for lymphadenectomy. Br J Surg 1994;81:1769-1770. 